\title{
COVID-19 Associated Large Vessel Thrombosis and Ischemic Stroke: A Case Series
}

\begin{abstract}
Ans Alamami ${ }^{1 *}$, Rabee Tawel', Abdussalam Elgrewi $^{2}$, Ahmed L M Abdussalam ${ }^{1}$ and Anam M Elarabi ${ }^{3}$

${ }^{1}$ Medical Intensive Care Department, Hamad General Hospital, Hamad Medical Corporation, Qatar 2Internal Medicine Department, Hamad General Hospital, Hamad Medical Corporation, Qatar ${ }^{3}$ Pulmonology Department, Hamad General Hospital, Hamad Medical Corporation, Qatar
\end{abstract}

*Corresponding author: Ans Alamami, Critical Care Department, Hamad General Hospital, Hamad Medical Corporation, Qatar

Received: December 04, 2020; Accepted: December 22, 2020; Published: December 29, 2020

\begin{abstract}
The novel severe acute respiratory syndrome coronavirus (SARS-COV-2) affects different people in different ways. Most infected people will develop mild to moderate respiratory flu-like illness and recover without the need for hospitalization. However, one of the not uncommonly observed extrapulmonary associations with SARS-COV-2 is developing severe large-vessel acute ischemic stroke. Moreover, COVID-19 virus-linked Cerebrovascular Accidents (CVA) were more severe and resulted in a higher risk for severe disability and mortality following acute insult. Although the pathophysiology is not fully understood, the neuro-targeting nature of SARS-COV-2 due to vascular injury and the hyperimmune response were plausible proposed mechanisms. Further research is warranted to have a deep insight into the possible mechanisms. Herein, we review the current literature and describe five patients we have encountered during the SARS-COV-2 viral pandemic.
\end{abstract}

Keywords: Coronavirus; SARS-COV-2; COVID-19; Stroke; Thrombophilia

\section{Abbreviations}

ARDS: Adult Respiratory Syndrome; NRBM: Non-Re breather Bag Mask; PCR: Polymerase Chain Reaction; IL: Interleukin; TNF: Tumor Necrotizing Factor

\section{Background}

The novel Severe Acute Respiratory Syndrome Coronavirus (SARS-COV-2) is a viral respiratory illness of the coronavirus family. It was first discovered in Wuhan, China, in December 2019 and rapidly became a global pandemic of SARS-COV-2. It is transmitted primarily through respiratory droplets, but airborne transmission concerns have been raised by the World Health Organization (WHO) COVID-19 presents with widely variable clinical manifestations such as cough, fever, shortness of breath, and its complications, like pneumonia with Adult Respiratory Distress Syndrome (ARDS), circulatory shock, severe inflammatory reaction, in addition to coagulopathy and thromboembolism [1].

COVID-19-associated coagulopathy ranges from mild thrombocytopenia to severe coagulopathy, meeting the International Society on Thrombosis and Hemostasis (ISTH) criteria for Disseminated Intravascular Coagulation (DIC). One of the most commonly observed coagulation abnormalities of COVID-19 is the raised D-Dimer and the reduction in serum fibrinogen levels [19], which are considered a marker of disease severity and therefore have been used to monitor disease activity. The underlying pathophysiology of Venous Thromboembolism (VTE) is related to endothelial injury by SARS-COV-2's direct effect on the vascular endothelium, particularly in those with well-established secondary sepsis, venous stasis $[7,13]$ and coagulopathy, especially in critically-ill patients [12].

Another key role in developing hypercoagulability in COVID-19 patients is the hyper-inflammatory response to SARS-COV-2 (cytokine storm syndrome), resembling the CAR-T associated cytokine release syndrome, mainly a serial cytokine rush particularly IL1, IL6 [1,4,9,14], TNF-alpha and IL8. These inflammatory mediators directly affect the vascular endothelium concurrently with the viral insult. They together activate the coagulation cascade resulting in arterial and venous thrombosis manifested as VTE, pulmonary embolism, arterial events such as ischemic stroke $[2,3]$ and peripheral limb ischemia.

Herein, we report five cases of confirmed COVID-19 who developed an ischemic stroke of varying severity during their COVID-19 disease course.

\section{Patient 1}

An 80 -year-old man with a past medical history of diabetes mellitus type 2 (Type 2 D.M.), hypertension, and prostate cancer on hormonal therapy, presented to the E.D. complaining of fever, generalized fatigue, cough, and shortness of breath for three days. Upon initial evaluation, he was in respiratory distress with oxygen saturation of $92 \%$ on a Non-Rebreather Bag Mask (NRBM). His laboratory investigations were significant for lymphopenia and elevated D-Dimer, C-reactive protein, and ferritin levels. A chest $\mathrm{x}$-ray showed bilateral perihilar infiltrates. His real-time Polymerase Chain Reaction (PCR) from nasopharyngeal swab was positive for COVID-19; therefore, we started him on azithromycin, hydroxychloroquine, ritonavir/lopinavir combination daily, steroids, and anticoagulation. He received tocilizumab for the significant underlying inflammatory process; then, he reported a new leftsided body weakness and tingling 24-hours after hospitalization. His physical exam revealed reduced power in the right upper and lower limbs with increased muscle tone. An urgent C.T. scan of the head ruled out acute intracerebral bleeding. MRI and MRA of the head of T2/FLAIR confirmed hyperintense acute infarct in the right parietal frontal lobe (Figure 1), and smaller multifocal areas of patchy acute infarcts in the left frontoparietal lobe, right more than left insula, bilateral temporooccipital regions, left caudate head, and tiny acute 


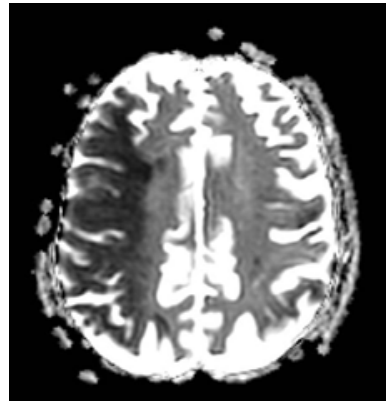

Figure 1: MRA head with T2/FLAIR showing hyperintense acute infarct in the right parietal-frontal lobes and smaller multifocal areas of patchy acute infarcts in the left frontoparietal lobe, right more than left insula, bilatera temporooccipital regions, left caudate head, and tiny acute lacunar infarct in the right cerebellar hemisphere.

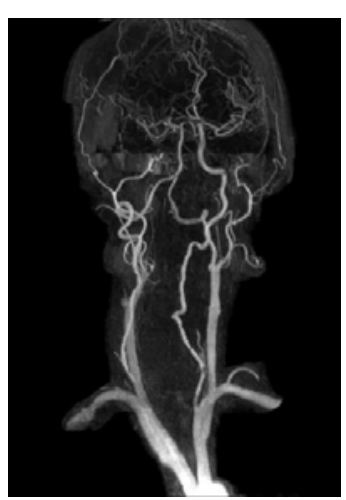

Figure 2: MRA of the head and neck showing occluded right Middle Cerebral Artery (MCA) from the origin in the neck.

lacunar infarct in the right cerebellar hemisphere in addition to the occluded right Middle Cerebral Artery (MCA) from the origin in the neck (Figure 2).

\section{Patient 2}

A 60-year-old man, diabetic and hypertensive with right nephrectomy for angiomyolipoma. We hospitalized him after testing positive for COVID-19 PCR from a nasopharyngeal swab. Initially, he was complaining of fever, cough, but he had no signs of respiratory distress. We started him on hydroxychloroquine, azithromycin, ritonavir/lopinavir, and methylprednisolone in addition to anticoagulation for mild COVID-19 pneumonia in a high-risk patient. On Day 12 of the disease course, the patient experienced an insidious onset of left-sided upper limb weakness with slurring in speech. Physical examination revealed left-side body weakness with left upper facial nerve palsy and dysarthria. His initial NIHSS was 22; however, shortly afterward, he started to become confused with a progressive deterioration in his conscious level mandating intubation and mechanical ventilation. An urgent CT-head with CT-perfusion confirmed a large area of a matched perfusion defects involving the whole right MCA territory, with no clear salvageable tissue. A CT Angiogram revealed a completely occluded right MCA. We deferred thrombolysis because of a significant risk of ICH development secondary to the large area of infarction. Hence, there are matched MCA territory changes, and there are no collaterals; with an ASPECT score of 3 , thrombectomy was not feasible either.

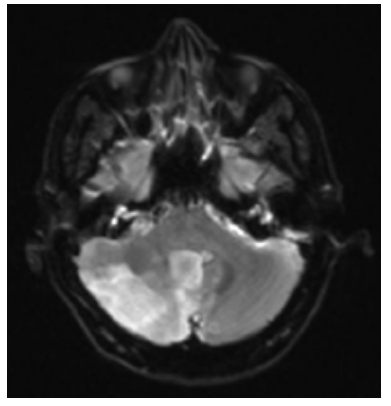

Figure 3: T2 Weighted head MRI confirmed multiple areas of late acute infarcts along with the posterior circulation territory in the right cerebellar hemisphere.

\section{Patient 3}

A 41-year man was previously healthy and has been in homebased quarantine after being in close contact with a COVID-19 patient before presenting to the E.D. with complaints of severe headache, dizziness, and vomiting 1-day duration. He was drowsy but following simple commands and moving all his limbs. CT-head showed a sizable ill-defined hypodense area noted in the right cerebellar hemisphere/ medulla suggestive of acute stroke in the right Posterior Inferior Cerebellar Artery (PICA) territory with corresponding edema and mild mass effect. With no evidence of hemorrhagic transformation. MRI and MRA confirmed multiple areas of late acute infarcts along with the posterior circulation territory in the right cerebellar hemisphere (Figure 3). A nasopharyngeal swab of COVID-19 real time-PCR turned out positive; we started the patient on azithromycin, hydroxychloroquine, ritonavir/lopinavir, steroids, and enoxaparin on day 3. The patient's condition deteriorated rapidly with a decreased conscious level, requiring intubation, without interval change on a repeat CT-head. 7-days later, his neurological deficit progressed to bilateral upper and lower limb weakness, and an MRI spine revealed spinal cord infarct at T1-T3 vertebral levels, C2-C3 disk levels, and C4 vertebral level. Further workup to identify a possible source for the thrombus, including a transthoracic echocardiogram, was unremarkable. On day 20, and after multiple failed weaning trials, we inserted a percutaneous tracheostomy and then transferred him to a rehabilitation facility.

\section{Patient 4}

A 42-year-old active smoker with no known past medical history. 2-days after being hospitalized for moderate COVID-19 moderate pneumonia and after receiving hydroxychloroquine, azithromycin, enoxaparin, methylprednisolone plus ritonavir/ lopinavir; he developed left-sided body weakness with facial asymmetry and slurring of speech of unknown time of onset associated with a sudden decrease in the level of consciousness with NIHSS- 9. A CT-scan brain perfusion and C.T. angiography showed a large area of matched perfusion defect noted in the right MCA territory with infarction involving the right front temporoparietal region and a filling defect in the distal segment of the right common carotid artery at its bifurcation. We did not offer thrombolysis as the time of stroke onset was unclear. He was managed conservatively with IV heparin, then changed to antiplatelets and a rehabilitation program for body weakness. 
Table 1: Patient characteristics summary.

\begin{tabular}{|c|c|c|c|c|c|}
\hline Parameter & CASE- 1 & CASE-2 & CASE-3 & CASE-2 & CASE-5 \\
\hline Age & 80 years & 60 years & 41 years & 42 years & 49 years \\
\hline Gender & M & M & M & M & M \\
\hline Risk factor & DM, HTN, Malignancy & DM, HTN & Non & NON & Non \\
\hline lymphocyte & $0.60 \times 10^{\wedge} 3 / \mathrm{uL}$ & $1.0 \times 10^{\wedge} 3 / \mathrm{uL}$ & $0.80 \times 10^{\wedge} 3 / \mathrm{uL}$ & 1.5 & $0.9 \times 10^{\wedge} 3 / \mathrm{uL}$ \\
\hline Platelets & $420 \times 10^{\wedge} 3 / \mathrm{uL}$ & $242 \times 10^{\wedge} 3 / u L$ & $280 \times 10^{\wedge} 3 / \mathrm{uL}$ & $482 \times 10^{\wedge} 3 / \mathrm{uL}$ & $371 \times 10^{\wedge} 3 / u L$ \\
\hline CRP & $331.6 \mathrm{mg} / \mathrm{L}$ & $220.4 \mathrm{mg} / \mathrm{L}$ & $<0.5 \mathrm{mg} / \mathrm{L}$ & $29.7 \mathrm{mg} / \mathrm{L}$ & $270 \mathrm{mg} / \mathrm{L}$ \\
\hline D Dimer & $30.71 \mathrm{mg} / \mathrm{L}$ FEU & $3.65 \mathrm{mg} / \mathrm{L}$ FEU & $2.92 \mathrm{mg} / \mathrm{L}$ FEU & $3.56 \mathrm{mg} / \mathrm{L} \mathrm{FEU}$ & $2.92 \mathrm{mg} / \mathrm{L} \mathrm{FEU}$ \\
\hline Ferritin & $1,841.0 \mathrm{ug} / \mathrm{L}$ & $257 \mathrm{ug} / \mathrm{L}$ & $185.0 \mathrm{ug} / \mathrm{L}$ & $596 \mathrm{ug} / \mathrm{L}$ & $820 \mathrm{ug} / \mathrm{L}$ \\
\hline Fibrinogen & $8.5 \mathrm{gm} / \mathrm{L}$ & $4.43 \mathrm{gm} / \mathrm{L}$ & $5.6 \mathrm{gm} / \mathrm{L}$ & $4.63 \mathrm{gm} / \mathrm{L}$ & $3.54 \mathrm{gm} / \mathrm{L}$ \\
\hline Glucose & $8.3 \mathrm{mmol} / \mathrm{L}$ & $9.1 \mathrm{mmol} / \mathrm{L}$ & $13.2 \mathrm{mmol} / \mathrm{L}$ & $6.8 \mathrm{mmol} / \mathrm{L}$ & $7.6 \mathrm{mmol} / \mathrm{L}$ \\
\hline \multirow{4}{*}{$\begin{array}{l}\text { Medication } \\
\text { provided }\end{array}$} & $\begin{array}{c}\text {-Unfractionated heparin } \\
\text { 5000mg TID }\end{array}$ & -Enoxaparin 40mg BID & -Enoxaparin 40mg BID & -Enoxaparin 40mg BID & -Enoxaparin 40mg BID \\
\hline & $\begin{array}{c}\text {-azithromycin 500mg } \\
\text { q24hr/5days }\end{array}$ & $\begin{array}{c}\text {-azithromycin 500mg } \\
\text { q24hr/5days }\end{array}$ & $\begin{array}{c}\text {-azithromycin 500mg } \\
\text { q24hr/5days }\end{array}$ & $\begin{array}{c}\text {-azithromycin 500mg } \\
\text { q24hr/5days }\end{array}$ & $\begin{array}{c}\text {-azithromycin 500mg } \\
\text { q24hr/5days }\end{array}$ \\
\hline & $\begin{array}{c}\text {-ritonavir/lopinavir 500mg } \\
\text { q24hrs/5days }\end{array}$ & $\begin{array}{c}\text {-ritonavir/lopinavir 500mg } \\
\text { q24hrs/5days }\end{array}$ & $\begin{array}{c}\text {-ritonavir/lopinavir 500mg } \\
\text { q24hrs/5days }\end{array}$ & $\begin{array}{c}\text {-ritonavir/lopinavir 500mg } \\
\text { q24hrs/5days }\end{array}$ & $\begin{array}{c}\text {-ritonavir/lopinavir 500mg } \\
\text { q24hrs/5days }\end{array}$ \\
\hline & $\begin{array}{l}\text { methylprednisolon 40mg } \\
\text { daily }\end{array}$ & $\begin{array}{c}\text { methylprednisolon } 40 \mathrm{mg} \\
\text { dail }\end{array}$ & $\begin{array}{l}\text { methylprednisolon } 40 \mathrm{mg} \\
\text { dail }\end{array}$ & $\begin{array}{c}\text { methylprednisolon 40mg } \\
\text { dail }\end{array}$ & $\begin{array}{l}\text { methylprednisolon } 40 \mathrm{mg} \\
\text { dail }\end{array}$ \\
\hline
\end{tabular}

\section{Patient 5}

EMS brought a middle-aged man with unknown past medical history after being found in a drowsy state by his neighbor. On physical exam, his Glasgow Coma Scale (GCS) was 9/15. An urgent CT-head angiography showed a filling defect at the basilar artery's bifurcation, causing posterior circulation acute infarction with a surrounding penumbra. His routine Chest X-ray showed increased bilateral broncho-vascular markings; however, he tested positive for the COVID-19 virus in nasal swab PCR and had a normal sinus rhythm on ECG. We did not offer him thrombolysis as the onset time is unknown, neither thrombectomy, as he already had an established infarction on the plane CT-head. The MRI head confirmed the previous C.T. findings and showed some areas of hemorrhagic transformation. Later on, the patient developed further deterioration in GCS, mandated intubation, and mechanical ventilation. 6-days into his course, he developed refractory hypotension and bradycardia followed by asystole and could not be revived with Cardiopulmonary Resuscitation (CPR).

\section{Discussion}

With the ongoing outbreak of COVID-19, we noticed a significant increase in ischemic stroke incidence among patients with a severe inflammatory response to SARS-COV-2-induced ARDS admitted to our high dependency and intensive care units [Table1]. The authors observed SARS-COV-2's associated ischemic stroke with the ongoing recognition of the neurological manifestations of COVID-19 $[4,5,16]$. Mao et al. described these manifestations in a retrospective observational case series of 219 patients in Wuhan, China, $41.1 \%$ of which had severe pulmonary disease, $36.4 \%$ elicited a neurological manifestation of which $5.7 \%$ attributed to cerebrovascular disease. [16].

In a retrospective cohort study of 1,916 patients who visited the emergency department in two academic New York hospitals, Mekler et al. found that 36 patients had an acute ischemic stroke in SARSCOV2 infection (1.6\%; 95\% CI, 1.1\%-2.3\%) in comparison to 3 out of 1,486 patients with influenza viral infections $(0.2 \%$; $95 \%$ CI, $0.0 \%$ $0.6 \%)[18]$.

The neuro-targeting nature of the virus can explain the correlation of SARS-COV-2 severity and ischemic stroke due to vascular injury and the hyperimmune response. These responses alter the bloodbrain barrier, permitting the virus to bind to the ACE2 receptor in glial cells, which, in addition to hypercoagulation, plays an important role in the development of ischemic stroke $[11,15]$.

Although the underlying pathophysiological process responsible for the development of stroke in COVID-19 has not yet been determined, different mechanisms related to the COVID-19 infectious process were postulated, such as the host's hyperinflammatory response to the exaggerated cytokine release. For instance, interleukins play an essential role in the inflammatory response and in COVID-19 patients; IL-1, a macrophage-secreted interleukin, is elevated, especially in severe COVID-19 cases. [4], Other inflammatory mediators responsible for activating acute-phase reactions like interferon-gamma [5], tumor necrosis factor-alpha, and IL-6 were also elevated in SARS-COV-2 infected patients $[8,9]$. IL-6 activity has a unique importance as it has considered a target for tocilizumab, an IL-6 receptor antagonist with possible alleviation of the SARS-COV2-associated cytokines storm and subsequently the severity of the infection [20].

Jenny et al. have addressed the relationship between inflammatory cytokines and risk for ischemic stroke risk in their cohort study. They found that raised IL- 6 levels were associated with an increased risk of ischemic stroke (mean 4.5 vs. 3.7ng/mL; $\mathrm{p}<0.001$ ) [14]. Another factor supporting this association is endothelial injury, as described by Varga et al. where the histopathology of different samples from three patients with SARS-COV2 infection confirmed evidence of viral endothelial invasion with subsequent accumulation of inflammatory cells attributed to the widespread of ACE2 receptor through the endothelial vascular lining [10].

A dysfunctional procoagulant state with ultimate activation of 
the coagulation cascade, an acceleration of the already established vasculopathy, and vascular thrombosis are keys in the cases mentioned above, explicitly numbered 1 and 2 . Those patients developed stroke secondary to large vessel disease with complete occlusion of the corresponding internal carotid artery.

About the SARS-COV-2 induced coagulopathy, the inflammatory process has been associated with an increased level of D-Dimer and fibrin degradation products. These two parameters' value was higher in severe CVOID-19 cases than their milder counterparts [17]. This has subsequently led to the prolongation of P.T. and APTT and a DIC picture with increased mortality [1]. The incidence of thrombotic complications in patients with severe SARS-COV-2 infection, especially those who required critical care admission, was high, which indicates the underlying coagulation derangement correlated with the viral burden and severity $[7,13]$. Panigada et al. described thrombo-elastography findings in a patient with COVID-19 admitted to the intensive care unit revealed a dramatic increase in D Dimer, fibrinogen, and von Willebrand factor. Factor VIII was decreased along with antithrombin [12].

\section{Conclusion}

The increased incidence of ischemic stroke was frequently encountered among patients with ARDS and a significant inflammatory response. We hypothesized that the underlying pathophysiology could be related to considerable inflammation, deranged coagulation, and viral cell invasion through endothelial ACE2 receptors; this finding warranted the suggestion of a full dose of anticoagulation for the hospitalized patient with moderate to severe COVID-19 pneumonia. Such observations need further studies to define the exact mechanism by which SARS-COV-2 induces ischemic stroke.

\section{Statement of Ethics}

Written informed consent was obtained from the patient/relatives for publication approval for publication was brought under the MRC number MRC-04-20-1040.

\section{Acknowledgment}

We also acknowledge the Medical Research Center at Hamad Medical Corporation for their support.

\section{References}

1. Tang N, Li D, Wang X, Sun Z. Abnormal coagulation parameters are associated with poor prognosis in patients with novel coronavirus pneumonia. Journal of Thrombosis and Haemostasis. 2020; 18: 844-847.

2. Paniz-Mondolfi A, Bryce C, Grimes Z, Gordon RE, Reidy J, Lednicky J, et al Central nervous system involvement by severe acute respiratory syndrome coronavirus-2 (SARS-CoV-2). Journal of Medical Virology. 2020; 92: 699702

3. Ntaios G, Michel P, Georgiopoulos G, Guo Y, Li W, Xiong J, et al. Characteristics and Outcomes in Patients With COVID-19 and Acute Ischemic Stroke: The Global COVID-19 Stroke Registry. Stroke [Internet]. 2020.
4. Yang $\mathrm{X}, \mathrm{Yu} \mathrm{Y}, \mathrm{Xu} \mathrm{J}$, Shu $\mathrm{H}$, Xia J, Liu H, et al. Clinical course and outcomes of critically ill patients with SARS-CoV-2 pneumonia in Wuhan, China: a single-centered, retrospective, observational study. The Lancet Respiratory Medicine. 2020; 8: 475-481.

5. Huang C, Wang Y, Li X, Ren L, Zhao J, Hu Y, et al. Clinical features of patients infected with 2019 novel coronavirus in Wuhan, China. The Lancet. 2020; 395: 497-506.

6. Magro C, Mulvey JJ, Berlin D, Nuovo G, Salvatore S, Harp J, et al. Complement associated microvascular injury and thrombosis in the pathogenesis of severe COVID-19 infection: A report of five cases. Translational Research. 2020; 220: 1-13.

7. Klok FA, Kruip MJHA, van der Meer NJM, Arbous MS, Gommers D, Kant $\mathrm{KM}$, et al. Confirmation of the high cumulative incidence of thrombotic complications in critically ill ICU patients with COVID-19: An updated analysis. Thrombosis Research. 2020; 191: 148-150.

8. Cheung $\mathrm{CY}$, Poon LLM, Ng IHY, Luk W, Sia S-F, Wu MHS, et al. Cytokine Responses in Severe Acute Respiratory Syndrome Coronavirus-Infected Macrophages In Vitro: Possible Relevance to Pathogenesis. Journal of Virology. 2005; 79: 7819-7826.

9. Qin C, Zhou L, Hu Z, Zhang S, Yang S, Tao Y, et al. Dysregulation of Immune Response in Patients With Coronavirus 2019 (COVID-19) in Wuhan, China. Clin Infect Dis. 2020; 71: 762-768.

10. Varga Z, Flammer AJ, Steiger P, Haberecker M, Andermatt R, Zinkernage AS, et al. Endothelial cell infection and Endotheliitis in COVID-19. The Lancet. 2020; 395: 1417-1418.

11. Baig AM, Khaleeq A, Ali U, Syeda H. Evidence of the COVID-19 Virus Targeting the CNS: Tissue Distribution, Host-Virus Interaction, and Proposed Neurotropic Mechanisms. ACS Chem Neurosci. 2020; 11: 995-998.

12. Panigada M, Bottino N, Tagliabue P, Grasselli G, Novembrino C, Chantarangkul V, et al. Hypercoagulability of COVID-19 patients in intensive care unit: A report of thromboelastography findings and other parameters of hemostasis. Journal of Thrombosis and Haemostasis. 2020; 18: 1738-1742.

13. Klok FA, Kruip MJHA, van der Meer NJM, Arbous MS, Gommers DAMPJ, Kant $\mathrm{KM}$, et al. Incidence of thrombotic complications in critically ill ICU patients with COVID-19. Thrombosis Research. 2020; 191: 145-147.

14. Jenny NS, Callas PW, Judd SE, McClure LA, Kissela B, Zakai NA, et al. Inflammatory cytokines, and ischemic stroke risk. Neurology. 2019; 92: e2375.

15. Fotuhi M, Mian A, Meysami S, Raji CA. Neurobiology of COVID-19. JAD. 2020; 76: 3-19.

16. Mao L, Jin H, Wang M, Hu Y, Chen S, He Q, et al. Neurologic Manifestations of Hospitalized Patients With Coronavirus Disease 2019 in Wuhan, China. JAMA Neurol. 2020; 77: 683-690.

17. Han H, Yang L, Liu R, Liu F, Wu K, Li J, et al. Prominent changes in blood coagulation of patients with SARS-CoV-2 infection. Clinical Chemistry and Laboratory Medicine (CCLM). 2020; 58: 1116-1120.

18. Merkler AE, Parikh NS, Mir S, Gupta A, Kamel H, Lin E, et al. Risk of Ischemic Stroke in Patients With Coronavirus Disease 2019 (COVID-19) vs. Patients With Influenza. JAMA Neurology [Internet]. 2020.

19. Connors JM, Levy JH. Thromboinflammation and the hypercoagulability of COVID-19. Journal of Thrombosis and Haemostasis. 2020; 18: 1559-1561.

20. Guaraldi G, Meschiari M, Cozzi-Lepri A, Milic J, Tonelli R, Menozzi M, et al. Tocilizumab in patients with severe COVID-19: a retrospective cohort study. The Lancet Rheumatology. 2020; 2: e474-84. 